\title{
Editorial \\ Building a Social Sustainable Society: Influence of Interventions and Training Programs on Organisational Climate
}

\author{
Martina Morando *(D) and Silvia Platania \\ Department of Educational Science, Psychology Section, University of Catania, 95124 Catania, Italy; \\ splatani@unict.it \\ * Correspondence: martina.morando@phd.unict.it
}

Citation: Morando, M.; Platania, S. Building a Social Sustainable Society: Influence of Interventions and Training Programs on Organisational Climate. Merits 2022, 2, 21-25. https://doi.org/10.3390/ merits2010003

Received: 8 February 2022

Accepted: 14 February 2022

Published: 16 February 2022

Publisher's Note: MDPI stays neutral with regard to jurisdictional claims in published maps and institutional affiliations.

Copyright: (C) 2022 by the authors. Licensee MDPI, Basel, Switzerland. This article is an open access article distributed under the terms and conditions of the Creative Commons Attribution (CC BY) license (https:// creativecommons.org/licenses/by/ $4.0 /)$.

\section{The Current and Contemporary Importance of Organisational Climate and Organisational Culture}

Even though the constructs of climate and organisational culture were developed and described for the first time decades ago [1-3], they are still extremely modern and important constructs, in terms of their implications and impact on this field of study. Indeed, carrying out in-depth studies on the issue, and understanding the predictors of these variables and the related outcomes, has an important impact at the academic and managerial levels. Over the years, a strong body of literature has focused on the importance of the organisational climate and on its implications at the individual, team and organisation levels. This literature suggested that by investing in, and focusing on, the organisational climate, each company has direct effects on individual and organisational wellbeing, and on the ROI (return of investment) of companies. Moreover, this care and engagement about organisational climate seems to fully meet the goal of promoting and implementing decent and sustainable work, a current problem and a very worthy aim [4].

Indeed, one of the key challenges of the 21st century is sustainability. In the current panorama, the goals promoted by the 2030 Agenda for Sustainable Development are particularly relevant, and have promoted 17 Sustainable Development Goals (SDGs). Some of these SDGs show a correlation with organisational systems, especially in the dynamics of risk management, demonstrating that it is important to give equal importance to economic and financial aspects, but also to variables of reputational, ethical, social and psychological nature. It is in this background that studies on climate and organisational culture have been, and are being, carried out, emphasising their importance on the issue of wellbeing and quality of life at the global level.

To date, the theoretical background has focused on describing the construct of organisational climate, indicating its multidimensionality [5-8]. Organisational climate can be defined as "shared perceptions of and the meaning attached to the policies, practices, and procedures employees experience and the behaviours they observe getting rewarded and that are supported and expected" within an organisational context [9] (p. 362).

Several contributions have confirmed the close and inescapable ties between the individual and the organisation, and their mutual influence. The signalling theory [10] is a clear example of this, underlining how employees' perceptions are directly related to, and shaped by, specific signals intended by the organisation. These signals are related to both the employees' experiences and to the messages that the organisation voluntarily conveys [11]. Even when such information is incomplete, employees shape their perceptions based on what is visible and perceptible [12]. The social exchange theory also provides us with the following interesting perspective: employees who perceive that the organisation pays particular attention to enhancing human capital, and to adopting valuable practices and policies, are encouraged to adopt and maintain such behaviours and attitudes, in order to have a form of positive social return $[13,14]$. While this conceptualization of organizational climate may appear to resemble the concept of organizational culture, in that both are 
concerned with the creation and influence of social contexts in organizations, they are two distinct constructs, with differing epistemology, theoretical foundations and methodological assumptions.

In critically reviewing the literature on the two constructs, important differences arise, whose comprehension influences the studies carried out and possible interventions at the organisational level.

Although culture and climate both have a foundation in the interaction and socialisation between group members, organisational culture is more related to the historical evolution of social systems, and the understanding of individuals' underlying values and assumptions, whereas the climate construct focuses on the impact that organisational systems have on organisational members.

According to Denison [15], the organisational climate could be understood as a factual set of organisational dimensions and salient features, combined with corresponding individual perceptions of those objective features. This consideration leads to organisational climate being interpreted as something relatively temporary and limited to some aspects of the social environment only. As a construct, it is, therefore, implied that organisational climate is more malleable and more easily susceptible to direct control or manipulation by managers within the organisation, who act on practices and policies that influence the factual dimensions and, indirectly, the employees' perceptions.

This malleability represents the real and tangible possibility to intervene with this construct. An in-depth study is useful to understand the antecedents and consequences of climate at the individual, group and organisational levels, and allows scholars, the community and organisations to interrogate and propose themselves for educational, action research and/or longitudinal interventions. The findings and information obtained are valuable for the whole society, which gains awareness of the beneficial effects, and economic and social spin-offs. In the logic of sustainability, these data could also be useful to create a series of best practices to be imitated, in order to achieve the aim of creating a virtuous community that is socially sustainable, of value, and competitive on the market. These interventions conceal a difficulty and an important challenge; if the climate itself is more malleable, at the same time, this leads to changes at all levels of the organisation, but, above all, it requires time, which is a fundamental element for acquiring stability and trust in employees. These operations cannot be improvised, nor can they exclude careful study and planning; there is a risk of causing negative psychological effects at the individual, team and organisation levels.

There are several key issues to consider when discussing the relationship between culture and climate. Although researchers traditionally made theoretical distinctions between culture and climate, a number of articles have explored their overlap $[4,15,16]$. The elements favouring this overlap mainly concern the outcomes produced and the interpretation of the key elements. Regarding the outcomes, it is suggested, by research, that the perceptions of climate are associated with a variety of important individual, group and organisational outcomes. These outcomes include reduced turnover intentions; improved job satisfaction; higher individual job performance; increased work motivation; higher levels of commitment and engagement; increased organisational citizenship behaviours; greater personal initiative and flexibility; improved wellbeing and quality of life [17-20]. The overlap also occurs when considering the key elements of practices, policies, procedures, and routines, which play fundamental roles in both the organisational climate and culture. They are viewed as artifacts in culture [1], while, in the climate literature, e.g., [21,22], they are viewed as the basis for the formation of climate perceptions. It is proposed that the set of actual practices, policies and procedures is the linking mechanism between culture and climate. Given this fact, studying culture and climate, and thinking about possible interventions and training on climate or culture, had the same importance, because they could both produce positive outcomes for individuals, communities and organizations. 


\section{The Need for Training and Intervention}

An increasing number of manuscripts have illustrated the potential of organisational interventions to improve organisational culture and climate [23-25]. Organisational interventions differ in their nature and complexity, involving different steps and timeframes, but, above all, requiring specific individual and organisational characteristics.

In the systematic review by Ouellette and colleagues [23], it was clear how self-efficacy, the perception of resources and the readiness to change become fundamental for the implementation of these interventions, and for their maintenance over time. Unfortunately, the current literature presents few contributions concerning the association between organisational climate and possible interventions or transfer training [24-26]. However, studies on this subject are becoming increasingly useful in fostering the organisational change required by contemporary challenges. Nowadays, the study of interventions and training aids the understanding of specific demands and resources of organisations in the current era and over time, but also facilitates the replicability of successful training interventions. Moreover, it could be useful to examine the possible moderators of that success, and to foster and gradually move from organisational support to organisational change, in order to measure the global and specific domains of organisational culture and climate over multiple time points. All this brings forth a reflection on the profound importance that organisational interventions could have and how much studies in this sense could contribute, in the spirit of moving science to service.

\section{The Organisational Climate Today: The Concept of Multiple Climates}

In recent years, the debate around the relationship between organizational climate and safety climate has become increasingly heated. This has happened due to recent changes in the focus of research, as researchers' attention has shifted from global to aspect-specific climates. In detail, it is assumed that each organisation may have a number of climates related to specific aspects, such as a safety climate, a diversity climate, a communication climate, and so on [27]. It follows that many of these specific climates may be present at the same time in a working environment, since they refer to different aspects of the same organisational context; hence, it is very interesting to study them individually and in relation to each other [28].

\section{The Purposes of Studies in This Field}

The importance of carrying out studies in this field could be summarised by two main reasons, apart from the more general reason of these studies contributing to the success of the company and boosting the performance level of the organisation in both the long and short term.

The first objective that these studies certainly achieve is to offer a broader understanding and awareness of appropriate organisational climate, which could improve the impact of organisational climate components on several outcomes at the individual, group and organisational levels. The identification of an appropriate climate becomes fundamental because it involves all workers at the various levels considered, without distinction or symmetry.

The second objective that these studies could achieve is to offer answers and some form of indication for the current challenges experienced by the labour market. Specifically investigating the safety climate or the diversity climate, their specific antecedents and protective factors, and the positive outcomes they have fosters an important implication and application, not only at the academic level, but mainly at the managerial level.

Therefore, we hope that an increasing number of studies will be carried out on the topic of organisational climate, which will also focus on the application of organisational and training interventions and their evaluation. The expected findings could provide valuable indications for the construction of best practices to be applied and imitated, and could contribute to the construction of an increasingly sustainable society, also at the social level, in the logic of science at the service of society. 


\begin{abstract}
Author Contributions: Conceptualization, S.P. and M.M.; resources, S.P. and M.M.; writing—original draft preparation, S.P. and M.M.; supervision, S.P. All authors have read and agreed to the published version of the manuscript.
\end{abstract}

Funding: This paper received no external funding.

Conflicts of Interest: The authors declare no conflict of interest.

\title{
References
}

1. Schein, E.H. Organizational Culture and Leadership, 2nd ed.; Jossey-Bass: San Francisco, CA, USA, 1992.

2. Litwin, G.H.; Stringer, R.A., Jr. Motivation and Organisational Climate; Division of Research, Harvard Business School: Boston, MA, USA, 1968.

3. Hall, D.T.; Schneider, B. Correlates of organizational identification as a function of career pattern and organizational type. Adm. Sci. Q. 1972, 17, 340-350. [CrossRef]

4. Nair, V.; Vohra, V. Culture, Climate and Sustainability in Organizations. In Sustainable Human Resource Management; Vanka, S., Rao, M.B., Singh, S., Pulaparthi, M.R., Eds.; Springer: Singapore, 2020; pp. 169-181. [CrossRef]

5. Paolillo, A.; Pasini, M.; Silva, S.A.; Magnano, P. Psychometric properties of the Italian adaptation of the Mor Barak et al. diversity climate scale. Qual. Quant. 2016, 51, 873-890. [CrossRef]

6. Törner, M.; Pousette, A.; Larsman, P.; Hemlin, S. Coping with paradoxical demands through an organizational climate of perceived organizational support: An empirical study among workers in construction and mining industry. J. Appl. Behav. Sci. 2016, 53, 117-141. [CrossRef]

7. Coda, R.; da Silva, D.; Custodio, I. Multidimensional configurations of the organizational climate construct. Int. J. Hum. Resour. Manag. 2015, 26, 1827-1847. [CrossRef]

8. Silva, S.; Lima, M.L.; Baptista, C. OSCI: An organisational and safety climate inventory. Saf. Sci. 2004, 42, 205-220. [CrossRef]

9. Schneider, B.; Ehrhart, M.G.; Macey, W.H. Organizational climate and culture. Annu. Rev. Psychol. 2013, 64, 361-388. [CrossRef]

10. Connelly, B.L.; Certo, S.T.; Ireland, R.D.; Reutzel, C.R. Signaling Theory: A Review and Assessment. J. Manag. 2011, 37, 39-67. [CrossRef]

11. Avery, D.R.; McKay, P.F.; Wilson, D.C. Engaging the aging workforce: The relationship between perceived age similarity, satisfaction with co-worker and employee Engagement. J. Appl. Psychol. 2007, 25, 1542-1556. [CrossRef]

12. Turban, D.B.; Greening, D.W. Corporate social performance and organizational attractiveness to prospective employees. Acad. Manag. Ann. 1997, 40, 658-672. [CrossRef]

13. Tucker, S.; Chmiel, N.; Turner, N.; Hershcovis, M.S.; Stride, C.B. Perceived organizational support for safety and employee safety voice: The mediating role of coworker support for safety. J. Occup. Health Psychol. 2008, 13, 319-330. [CrossRef]

14. Brondino, M.; Silva, S.A.; Pasini, M. Multilevel approach to organizational and group safety climate and safety performance: Co-workers as the missing link. Saf. Sci. 2012, 50, 1847-1856. [CrossRef]

15. Denison, D.R. What is the difference between organizational culture and organizational climate? A native's point of view on a decade of paradigm wars. Acad. Manag. Rev. 1996, 21, 619-654. [CrossRef]

16. Ostroff, C.; Kinicki, A.J.; Muhammed, R.S. Organizational culture and climate. In Handbook of Psychology: Industrial and Organizational Psychology, 2nd ed.; Weiner, I.B., Schmitt, N., Highhouse, S.W., Eds.; John Wiley \& Sons: Hoboken, NJ, USA, 2013; Volume 2, pp. 643-676.

17. Castro, M.L.; Martins, N. The relationship between organisational climate and employee satisfaction in a South African information and technology organisation. J. Ind. Psychol. 2010, 36, 1-9. [CrossRef]

18. Abdulkarim, R.M. The Relationship between a Leader's Self-Perceived Level of Emotional Intelligence and Organizational Climate, as Perceived by Organizational Members. Ph.D. Thesis, Grand Canyon University, Phoenix, AZ, USA, 2013.

19. Platania, S.; Paolillo, A.; Silva, S.A. The Italian Validation of OSCI: The Organizational and Safety Climate Inventory. Safety 2021, 7, 22. [CrossRef]

20. Rožman, M.; Štrukelj, T. Organisational climate components and their impact on work engagement of employees in medium-sized organisations. Econ. Res.-Ekon. Istraz. 2021, 34, 775-806. [CrossRef]

21. James, L.R.; McIntyre, M.D. Perceptions of organizational climate. In Individual Differences and Behavior in Organizations; Murphy, K., Ed.; Jossey-Bass: San Francisco, CA, USA, 1996; pp. 416-450.

22. Schneider, B.; Gunnarson, S.K.; Niles-Jolly, K. Creating the climate and culture of success. Organ. Dyn. 1994, 23, 17-29. [CrossRef]

23. Ouellette, R.R.; Goodman, A.C.; Martinez-Pedraza, F.; Moses, J.O.; Cromer, K.; Zhao, X.; Pierre, J.; Frazier, S.L. A Systematic Review of Organizational and Workforce Interventions to Improve the Culture and Climate of Youth-Service Settings. Adm. Policy Ment. Health 2020, 47, 764-778. [CrossRef]

24. Peiro, J.M.; Nielsen, K.; Latorre, F.; Shepherd, R.; Vignoli, M. Safety training for migrant workers in the construction 941 industry: A systematic review and future research agenda. J. Occup. Health Psychol. 2020, 25, 275-295. [CrossRef]

25. Vignoli, M.; Nielsen, K.M.; Guglielmi, D.; Mariani, M.G.; Patras, L.; Peiro, J.M. Development of safety training for migrant 978 workers in the construction industry. Saf. Sci. 2021, 136, 105124. [CrossRef]

26. Blume, B.D.; Ford, J.K.; Surface, E.A.; Olenick, J. A dynamic model of training transfer. Hum. Resour. Manag. Rev. 2019, 29, 270-283. [CrossRef] 
27. Paolillo, A.; Silva, S.A.; Carvalho, H.; Pasini, M. Exploring patterns of multiple climates and their effects on safety performance at the department level. J. Saf. Res. 2020, 72, 47-60. [CrossRef] [PubMed]

28. Kuenzi, M.; Schminke, M. Assembling fragments into a lens: A review, critique, and proposed research agenda for the organizational work climate literature. J. Manag. 2009, 35, 634-717. [CrossRef] 